\title{
Building Productive Collaborations: Creation of A Technological Research and Development Unit (UIDT) of the ICAT in the General Hospital of Mexico
}

\author{
Luis Roberto Vega González ${ }^{1}$, Crescencio García Segundo ${ }^{1}$ \\ ${ }^{1}$ Instituto de Ciencias Aplicadas y Tecnología, UNAM, Circuito Exterior S/N, Ciudad Universitaria, A.P. 70-186, Alcaldía \\ de Coyoacán, CP 04510, Ciudad de México, México \\ Correspondence: Luis Roberto Vega-González, Secretaría de Vinculación y Gestión Tecnológica. Tel: (55) 5622-8602 \\ ext. 1135 and 1185; Fax 5622-8626, E-mail: 1rvg@ servidor.unam.mx; roberto.vega @ICAT.unam.mx.
}

Received: February 15, 2019

Accepted: March 7, 2019

Online Published: March 27, 2019

doi:10.11114/bms.v5i1.4177

URL: https://doi.org/10.11114/bms.v5i1.4177

\begin{abstract}
Nearly seven years after the signing of the Collaboration Agreement for the establishment of a Research and Technological Development Unit (UIDT, from Spanish) of the Applied Sciences and Technology Institute (ICAT, from Spanish), previously Applied Sciences and Technological Development Center (ICAT, from Spanish) of the National Autonomous University of Mexico (UNAM, from Spanish) within the General Hospital of Mexico "Eduardo Liceaga" (HGMEL, from Spanish), in this article we propose that there have been diverse human and organizational factors that allowed a smooth and nice birth of the institution and it seems there are good medium term consolidation perspectives. In a first exploration the UIDT has favored the processes of interchange of information and interdisciplinary communication between physicians and specialists of the health sector with the UNAM's physicists and engineers to reach agreements for the development of R\&D trans-disciplinary projects with high social impact potential. Through the results that are observed up to now, we note that the joint work between the parties has led to the development of different projects whose protocols have been approved by the corresponding medical, ethical and academic committees. Besides the conventional academic results there are emerging some specific technological results in the fields of medical devices, computer programs and a pair of technological transfers very promising in terms of the wide number of patients that will use them, as the cranial prostheses case or a hepatic pre-diagnostics auxiliary software method. This paper reviews various relevant organizational aspects resulting from the establishment of the UIDT and the lessons learned during the process.
\end{abstract}

Keywords: technological alliances, academic university and health sector, Mexico

"Nothing is more difficult to carry out, more dangerous to drive, or more uncertain success than taking the initiative in the introduction of a new order of things."

Maquiavelo

\section{Introduction}

Due to the increasing complexity of the modern world, nowadays, no organization can solve its fundamental issues or objectives by itself and requires the help of other organizations, which, through services, diverse collaborations or projects, provide products, human resources, materials, technologies, consultancies; etcetera. Therefore, the solution to many of these issues becomes, an opportunity, since it requires organizations to collaborate in alliances, networks, supply chains or strategic partnerships.

Collaborating organizations can obtain results that could be impossible if they developed them individually. To face the challenges of modern world it is necessary to work jointly. In that sense collaboration is always required; independently if it is a matter of doing innovations, finding solutions, improving products durability, improve the offered services quality, look for sustainable actions, strengthen security, and look for user's benefits among many other objectives.

For Kaats y Opheij, (2012), organizations must learn to collaborate because working in this fashion must yield benefits in any of the following fields: (a) new market development, (b) get cost advantages, (c) access to new technology, (d) new knowledge development, and (e) external organizational pressures handling. Paixão et al (2014) indicate that the 
main purposes of an organization to establish cooperation agreements with other companies, universities or external agents, are: sharing investments and risks, accelerating project developments, and accessing resources and competences not available internally.

Normally, two collaborating organizations are different regarding their size, objectives, human resources and structures. One of the main problems partner organizations face, is the ambiguity; therefore, it is required a language and a climate that could facilitate the collaboration since confusion is generated frequently because of languages, expectative and perceptions differences. (Kaats y Opheij, 2014).

For Stone and Lane (2012), the technological alliances implementation in the case of public healthcare fields, is an opportunity to foster knowledge translation concerned with implementing research findings to generate positive impacts for patients and professionals such as improve quality of life and the development of efficacious treatment protocols, biomedical devices, instruments and so on.

In the present work we will discuss the way the technological alliance between the General Hospital of Mexico (HGMEL) and the Instituto de Ciencias Aplicadas y Tecnología (ICAT, 2018) of the National Autonomous University of Mexico (UNAM) was done, for the establishment of a Unit for Research and Technological Development (UIDT) within the Hospital. The UIDT's organizational evolution through its life span, is also reviewed.

Naturally, there have been a number of challenges that it has been necessary to overcome, inherently to the fact that both are complex organizations with the common objectives of improving social wellness and human resources formation; nevertheless, their main working fields areas are different since the Hospital must provide health services and perform medical research and development, while the ICAT's objectives are research and technological development in the fields of instrumentation, techno-sciences, science and technology education, and communication and information technologies.

The technological alliance of complex organizations is a singular importance issue, because the members of the partner organizations domain distinct knowledge disciplines, situation that is a strength because it permits the boarding of more complex problems, but at the same time is a debility since the development of effective inter-disciplinary communication forms is required.

Besides, the alliance objective was the establishment of a new organization, what constitutes a substantial change, that although it could have been planned, it surely will propitiate organizational adjustments and sometimes changes in the direction allies move forward.

Another fundamental aspect of technological alliances or cooperative societies is the need to solve practical operational problems, as the executive decision making with ambiguous power structures, for which, it is required personal and cultural harmony promotion when there is limited control over the working teams. When the technological alliance objective is the creation of a new sub- organization, a relevant aspect is the unit's governance definition.

\section{Literature Review}

\subsection{Complex Organizations and Organizational Change Theory}

Everything changes, climate, seas, the universe, heaven, nature and so on. Change is intrinsically human as organizations are. Then, organizations change. Tripon \& Dodun (2011), define an organization as "a consciously coordinated social entity, with a relatively identifiable boundary, which functions on a relatively continuous basis to achieve a common goal or a set of goals". Moreover, an organization can be understood as an open system that interacts with its environment.

One important feature of the open system organization is the dynamic homeostasis. The system reaches a certain state of equilibrium and tends to maintain it against the inner or outer forces that attempt to modify it. Otherwise said, there are a system's tendency to self-preserve, to preserve its status-quo and its state of equilibrium. Nevertheless, systems become in time more elaborate, specialized and complex; this process is entitled differentiation. The greater the difference is, the greater becomes the need to integrate and coordinate; in other words, the need for leadership and management, in the case of organizations.

The organization's differentiation is an organization's change which is more than a change defined as just "a new state of things, different from the old state of things". (Bate, 1994). When we talk about "organizational change", we are talking about a change not only in the organizational activities, but in the operational processes of serving customers, of production, of logistics, culture and so. Besides these aspects, organizational change also covers changes that appear in work processes and in their subsystems.

In management literature there is a clear distinction between first and second order organizational changes. (Watzlawick, et. al, 1974). First order or incremental continuous changes may involve adjustments or improving systems, processes or structures, but does not involves fundamental change in strategy, core values or corporate identity. These types of changes maintain and develop an organization. (Newman, 2000). Paradoxically, these changes can be designed to support 
organizational continuity and order.

Second order, transformational or discontinuous change means a radical transformation, and fundamentally alters the organization at its core. Second-order change entails not developing but transforming the nature of the organization.

The directed transformation of an organization is as being embarking in designing, developing, and implementing a complex system that will have wider impact, a new set of challenges looms even larger. Certainly, technical challenges still exist; they always will. However, if our organization is a new system that affects larger, more heterogeneous groups of people and more organizational areas, the major challenges to systems success often become more behavioral than technical. To Lorenzi and Riley (2000), the changes administration requires is the promotion of higher organizational capabilities to support change management.

Organizing in chains and networks take organizations to a third level of systemic change or transition (de Witte et al. 2012; Kaats and Opheij, 2014). High management normally is the operator of those changes because must be heading reorientation changes and need to be prepared to softly direct and accompany other organization's members through the reorientation change timing because attitudinal and cultural differences can have profound implications on the ways people perceive, react and handle the challenges of change situations. The new expected organization is produced by the transformation and the operands are the people and organization's areas directly involucrate.

Ben-Eli (2008), propose that there are four factors to overcome and manage the change difficulties; they are: the complexity factor, related to the large number of variables and interactions among them; the epistemic factor, related to the persistent mental models of the stakeholders; the structural factor regarding the fundamental concept that when look for different behavior from an existing one in the organization, it would require a different underlying structure. And finally, the inertia or resistance to change factor. These factors are not only obstacles for change but when management does not use the antidotes for them, they drive organizations into crisis conditions of requiring second order change interventions.

To study an organization, we can use theory of physical dynamic systems. A complex organization can be seen as a social system that may adapt to changes in their environments using reflexive mechanisms as adaptation and learning, which cannot be described fully in terms of input and output flows. (Leydesdorff, 1997). Complex systems, on the other hand, consist of complicated interactions between and interferences by players (individuals, organizations, and institutions); the systems do not appear to have any clear boundaries and the main operational lines are not identifiable by their nature.

For Kaats and Opheij, (2014), complex systems are characterized by processes such as coincidence, emergence, and nonlinear developments that are almost impossible to predict, but that do result in renewal and innovation. Complex systems are both complicated and complex, which makes them partly explicable, but also partly inexplicable. We can understand some parts of complex systems through rational analysis and the application of laws and patterns, while we can only follow other parts as observers since they are established because of complicated interactions between autonomous players and variables. This means that executives need skills for dealing with both complicated and complex situations. This means that executives need skills for dealing with both complicated and complex situations. But their most important skill is their ability to determine a repertoire of the actions required to maintain the system stable and to know when those actions becomes more effective.

In brief, the management of social systems in general requires a systemic, multi-dimensional, multi-level approach, tackling all the relevant facets in an integrated, holistic, coherent manner. Managing significant transformations, in this context, requires a demanding balancing act between stability and change; order and freedom; autonomy and integration; tradition and innovation; planning and laissez-faire. Second, the time axis is urgent in relation to solutions. Underlying conditions mean operating in uncharted territory, with little instructive precedence and no manuals or accurate road maps. A successful change management effort requires comprehensiveness, coherence and creativity. (Ben-Eli, Op. Cit, p.7).

The creation of a new organization's units as a Peripheral Unidad de Investigación y Desarrollo Tecnológico (UIDT) for a research and development center, can be understood as a second order organizational reorientation change in the way for a third order systemic transition change in the medium term. According to Nadler and Tushman, (1995) reorientation is an anticipatory, discontinuous change that involves a major modification of the organization but by building on past strengths and history. A second order organization change requires management intervention, in the very least, using linear, simplistic approaches to change.

A peripheral Unit is like a new subsystem derived from both allies, which of course will have its own work time and frequency; nonetheless, for a good operation, it will be necessary to be synchronized and harmonized with both the Center's and the Hospital's operations. 


\subsection{Public-Private Partnerships (PPP) and Public-Public Partnerships (Pu2P) in Health}

Although the main issue to be addressed in this work is the partnership between two public organizations, it is interesting to note that many of the factors that affects public-private partnerships in the field of health, are common to those publicpublic in the same field.

Is well known that public and private organizations have significantly different goals, values and processes, in that regard Ramiah and Reich (2006) stated that there is increasing global recognition of the role and effectiveness of public-private partnerships (PPP's) in addressing global health issues. They indicate that in the United States, partnerships are increasingly viewed as an important approach for improving community health, as illustrated by the 25 partnerships in the Community Care Network Demonstration Program. Also, public-private ventures are being adopted for disease management projects in Europe and the United Kingdom. In developing countries, PPPs are emerging as one component of efforts to provide public services and public infrastructure.

Nevertheless, partners are advised to invest in extensive planning and learning in a process of an incremental engagement toward collaborations of intensive communication, and exchange of multiple resources at various levels of organizations. Porter and Kramer (1999) recommend that partners be closely involved with the implementation of projects to create value.

A dilemma exists between the growing desire for highly collaborative partnerships and the lagging capacity to manage the complex relationships that emerge in such partnerships. Either way public- private partnerships have transaction costs. Parker and Hartley (2003) have studied the economics of contracting in UK defense sector, the role of transaction costs and relational contracting.

The emergence of global health partnerships acts as facilitators of access to medication and to have equity of access to care for many sicknesses in underdevelopment countries as Africa and India. (Sheikh et al, 2006; Zisuh Ngoasong, 2009).

In their study of more than one hundred global health partnerships (GHP), Buse and Harmer (2007) found seven unhealthy habits of the common governance practice that produce undesirable results. Those are the following: (a) alignment of parts out of synchrony, (b) global partnerships not representative of their stakeholders, (c) poor governance, (d) vilification of the public sector, (e) inadequate finance, (f) poor harmonization, and (g) inadequate incentives to partner facing staff.

\subsection{Technological Alliances, Inter-Organizational Collaboration}

Kaats and Opheij, (2014), define collaboration between organizations as a form of organizing in which people from autonomous organizations go into durable agreements and, by doing so, mutually harmonize elements of the work between themselves. This results in a wide range of collaborative partnerships with a durable intention, but still with a finite duration. Kaats and Opheij, (2014, pp. 14), also define five characteristics of collaboration: (1) a high degree of interdependence, (2) an obscure center of power, (3) a new reality, (4) the attractive power of heterogeneity, (5) a context in constant flux.

Some decades ago, the source of innovation for organizations was solely its internal R\&D function therefore limited interaction with external actors take place. Chang et al (2002) presented a partnership program for public- private early stage technology development. Today public and private organizations have looked beyond their organizational boundaries and engaged in inter-organizational collaborations to obtain knowledge and innovations. This is known as open innovation. (Chesbrough, et al, 2006; Lichtenthaler, 2011). Strategic Alliances may well have become one of the most commonly adopted firm strategies, for the first decade of 2000 's, producing a proliferation of collaborative activity. For example, more than 10,000 newly created partnerships are created yearly in the biotechnology areas and Arthur D. Little and Price Waterhouse Coopers estimates that between 25 to $50 \%$ of the Pharmaceutical R\&D budget is spent in alliances. (De Rond and Bouchikhi, 2004)

Research on many topics around technological alliances have been intensively realized for both, private and public organizations. Research have included how alliances are initiated, operated, evaluated and the various internal and external factors that influence alliance development progress and the foundations for a model of strategic alliance evolution. (Wohlstetter et al., 2005)

Kim (2015) has developed the interesting investigation area of the development of a financing model related to funding medical equipment technology (MET) and its transfers to developing countries in a public- private partnership.

Since collaborative networks became increasingly larger, Calvin et al (2014), addressed the topic of the importance of the position that takes the firm within the alliance network, central or peripheral and Ho-Sung and Sun-Young (2014) have proposed organizations need to configure a portfolio of technological alliances. Lerner and Merges (1998), have pointed out the need to carefully allocate in the contractual agreements for technology alliances, the right to make decisions about issues that cannot be contractually specified or control rights. 
Das Rajesh Kumar, (2011), points out that there is a need to recognize that alliance partners are in a state of interdependence that may be a precursor of potential conflicts in the alliance; therefore, another critical issue is how the partners manage the interdependence that exists between them. He concludes that the management of interdependence necessitates extraordinary negotiation skills.

Although the definition for collaboration given by Huxham and Vangen, (2005, p.4), is simple: "any situation in which people are working across organizational boundaries toward some positive end", to start and maintain a collaboration is not too simple. In first place we need to define the necessity, and the essential characteristics and reasons for collaborating for minimizing misunderstanding, and the resulting discord that often surrounds inter-organizational relations. Collaboration is about establishing connections: connections between people, connections between communities, and connections with the world we live in. In that regard, strategic alliances are voluntary collaborations between organizations that involve product exchange, sharing or co-development, technology development or the provision of services that pursue a common set of goals (Gulati, 1998; cited by Lin and Darnall, 2014). For Lin and Darnall (2014), the motivations to form strategic alliances are: the share of decision-making risks, resource-based, institutional, the desires to enhance internal competencies and organizational learning.

In their theses research on Sweden automotive industry, Gustafsson \& Magnusson (2016), mention that interorganizational collaborations are not a new concept. Inter-organizational relations take the form of inter-company networks, strategic alliances, network alliances, various market transactions, and so. They found that even practitioners find inter-organizational collaborations key for their organizations, the process produced much confusion for them. They propose the following dimensions for collaboration: (a) structural dimension, (b) trust and mutuality and (c) the social dimension. Among them the dimension of trust and mutuality is considered the most important, "Trust can act as a substitute for governance mechanisms, which currently are time-consuming and costly activities".

Everyday more public health organizations are engaged in the building of alliances and networks for innovation and knowledge production. (Suarez-Balcazar et al., 2005). Innovative alliances, participatory research and technological alliances for public health have been widely discussed since the last quarter of the twentieth century (Mantoura et al. 2007). Peters and Muraleedharan (2008) have discussed collaborative mechanisms in India Health sector to improve accountability and finance control of the sector; Nelson et al (1998) talk about the position of American public Health Agencies when they commit strategic partnerships concluding that prior to implementing changes in functioning, structure, and/or future strategies, the heath agency should assess its internal readiness to commit to creating these substantial alterations.

Created in 1971, by 2012 ICAT had grown and developed academic groups working in sensors, instruments and systems related to human health, clearly, the institution had the need to establish a peripheral unit at the Hospital General de México, to have access to the patients with medical supervision for the development and validation of concept testing's and validation of the technological prototypes and the clinical testing protocols obtained as result of their research projects. At the same time, different Hospital medical services required to have access to high qualified technical people capable to develop new instruments, diagnostic systems and software to help to attend patients. These two conditions seeded the bases for the strategic alliance of both parts.

\section{Case: Establishment of the ICAT's UIDT in the Mexico's General Hospital "Eduardo Liceaga"}

\subsection{The Applied Sciences and Technology Institute}

The Applied Sciences and Technology Institute (ICAT) is part of the Scientific Research Subsystem of the National Autonomous University of Mexico (UNAM).

It was created as a service entity in 1971 with the name of Instruments Center with the main objectives of developing didactic instrumentation for the teaching of science in the different laboratories of the bachelorship UNAM's System and provide maintenance to the equipment and instruments other UNAM's entities already had. During its first 20 years the center's personnel was exclusively constituted engineers and designers who made nearly mono disciplinary simple technology projects requested mostly by other university faculties and research institutions.

Towards the third decade of the center's life, the first research fellows were contracted and soon the center change its orientation from a service center to a research and development center.

In 2002 with the approval of the UNAM's corresponding authorities the institution changes its name from Instruments Center to Applied Science and Technological Development Center, a new entity having around a three dozen of researchers and more than fifty academic technicians who worked out multidisciplinary R\&D projects in diverse knowledge fields.

In 2018 , the Institute celebrated its 47 th anniversary, now is a complex organization that work on research and technological development $(\mathrm{R} \& \mathrm{D})$ projects in which professionals of distinct disciplines participate with different 
experience levels and in different knowledge fields.

Its orientation is very clear, both research and technological development areas must direct their efforts to develop projects that provide integral technological solutions to external organizations that demand technology. The guideline is that the ICAT's technologies must help to improve the competitiveness of the requesting organizations. Sometimes Institute's personnel develop reverse engineering to improve or adapt existing technology trying to eliminate importations and technological dependence.

Figure 1 shows some project examples developed by the center along its life span. Highlighting relevant aspects of the center's evolution, specifically the type of technology versus the disciplinary approach required to develop them.

Currently, the academic personnel are about $45 \mathrm{PhD}$ researchers and about 70 academic technicians who are professionals, specialists and masters in the different fields of engineering, chemistry, pedagogy, teaching, industrial design, among many other knowledge fields. There are also about 200 Master and PhD students and about 200 support people for operation and administration of labs and intendance. The ICAT is organized in the following Departments: Measurement and Instrumentation, Techno-Sciences, Optics and Microwaves and Information Technologies. It can be seen a broad diversity in its working fields; nevertheless, this is a strength because the diversity of the disciplines that the academic members of the center have, has fostered the development of multidisciplinary capacities in the organization.

ICAT focus is the knowledge generation and its application to technology development. It is not a goods and service producer organization. Through the years its academic groups have increasingly carried out technology development projects contracted and financed by public and private external organizations. Analyzing the type of multidisciplinary work-based projects developed within the last years, ICAT's application areas became clear: Health, Science and Technology Education, Energy, Environment and Industry.

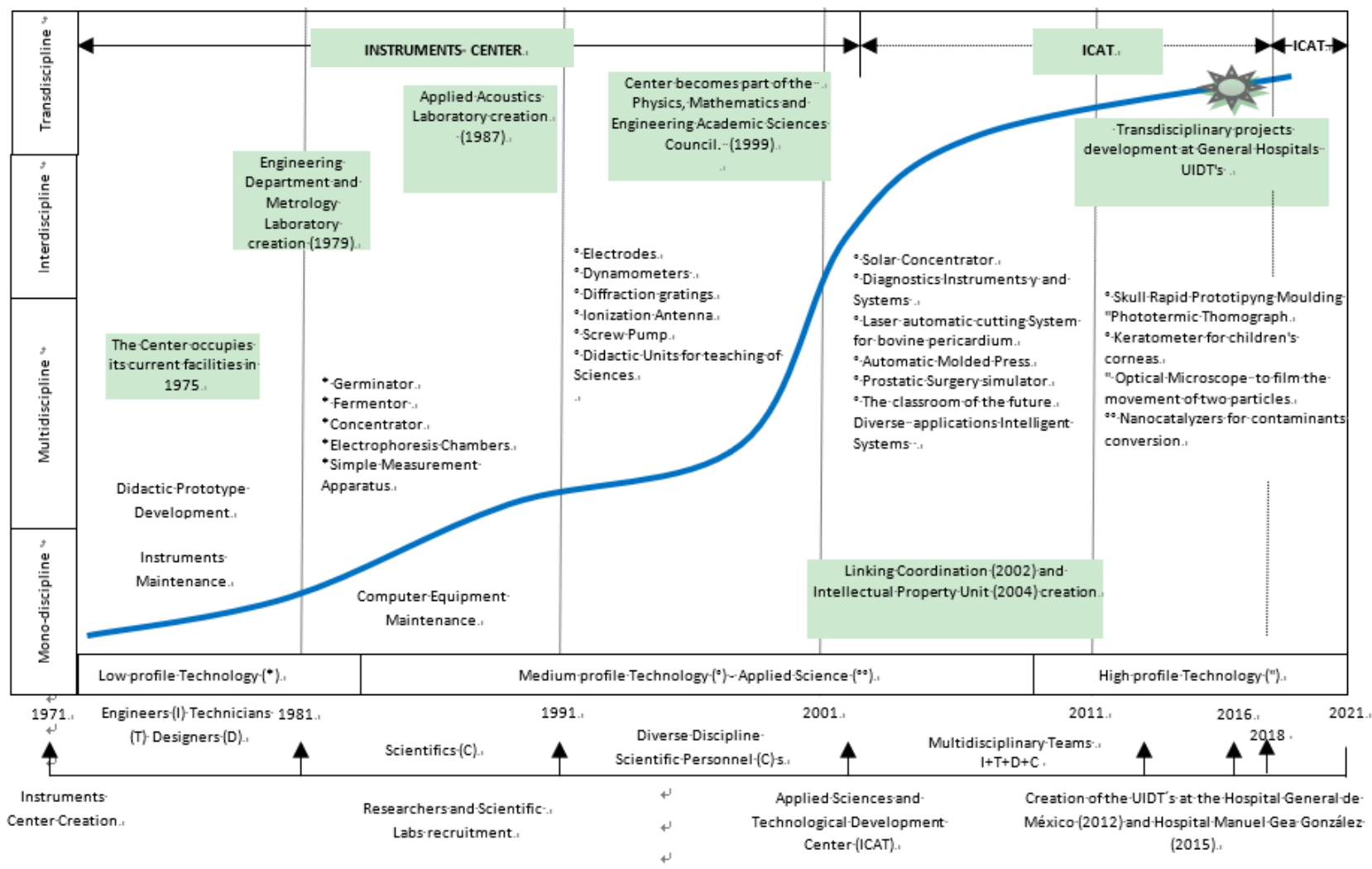

Figure 1. ICAT's technological and disciplinary evolution

During that period, the academic groups of the center, produced academic results such as books, scientific articles in indexed journals, trained human resources and taught at the UNAM's faculties. They also developed an important number of prototypes, including a good number of technological systems and services for many different organizations. Some results were: 23 electromechanical prototypes, 65 electronic instruments, 14 educative prototypes, 4 process technologies, 23 software and expert systems, and 15 applied science technological prototypes. 


\subsection{ICAT Approaches the Health Area}

The academic relation among UNAM's Physics, Mathematics and Engineering researchers with colleagues from the health knowledge and research areas was casuistic for many decades. Notably some ICAT's academics collaborated with academics from the Medicine Faculty and with some physicians working for diverse Health Sector Hospitals, by the end of the eighties, but it was not until the first years of this century that those collaborations became intense.

By the first quarter of 2002, diverse ICAT's academic groups received an invitation from the Applied Biotechnical Department of the National Cardiology Institute (INC, from Spanish), to realize technological development projects related to cardiac valves or bio-prostheses with economic financing coming from the Health Sector Fund of the National Council of Science and Technology (CONACYT, from Spanish). The academic groups of Electronics, Micromechanics and the Prototypes Section of the ICAT collaborated with physicians and biomedical engineers from the INC and developed interdisciplinary projects whose results were the first versions of a cardiac valve tester and a machine for manufacturing cardiac valves mounting rings. Later, in 2004 the INC invited academic groups of Micromechanics and Nonlinear Optics again to participate in a project to build an automatic bovine pericardium laser cutting system to optimize the biologic cardiac valves manufacturing.

In 2007 Mexico City government authorities created the Science and Technology Institute of the Federal District (ICYTDF) with the purpose to stimulate the technology development to help in high social impact problems solution for the inhabitants and public organizations located within the Mexico City Federal District. A second objective of the ICYTDF was to impulse the creation of different size enterprises in the city.

Previously, in 2006 at the different hospital levels of the Ministry of Health of the Federal Government it was noted that the behavior of Breast Cancer $(\mathrm{CaMa})$ had become a first importance health problem, therefore this sickness was declared a national epidemic by the Sanitary Authorities.

By the end of 2007, the Health Secretary of the Federal District asked the help of the ICYTDF to face the problem in the City of Mexico. In 2008 the ICYTDF invited ICAT to participate presenting research and development projects to obtain diagnostics technologies, measuring instruments and software to fight the sickness.

After a project selection and evaluation period, it was signed a collaboration agreement between the ICYTDF and the ICAT. The ICYTDF assigned funds for the development of some multi and inter-disciplinary projects by different academic groups, among them: Mammary tomography system based in photo thermo techniques, computerized assistance system for mammary cancer (MaCa) early detection, dense media objects detection for mammary applications, statistical methods library for epidemiologic research and a prototype of a support for the safe transfer of a digital mastograph mounted on mobile units.

The resulting prototypes and systems were delivered by ICAT to the ICYTDF who at its time delivered them to the user entities of the Health Sector. The final relation among ICAT academics and the final medical users consolidated the interdiscipline essence of the projects. Between 2009 and 2012 through annual different public project calls, ICYTDF provided financial support to the ICAT for the development of almost three dozen projects in various fields of medical science and technology.

\subsection{The Relationship of the ICAT and the Hospital General de México}

The General Hospital of Mexico was founded on February the 5th, 1905, by the President Porfirio Diaz. It is currently named after its founder Dr. Eduardo Liceaga who was its first Medical Director; in Spanish Hospital General de México "Dr. Eduardo Liceaga", (Sociedad Médica del Hospital General A. C., 2016). It is a public assistance institution belonging to the Ministry of Health of Mexico, it is part of a network of six hospitals that provide public health in the central area of the country, located in Colonia Doctores a few steps of the General Hospital metro station, line 3 of Mexico City. (Wikipedia, 2018)

The HGMEL has three sections: medical specialties, surgery and diagnostics and treatment. Its medical personnel give more than 1000 daily medical consultations in the different medical specialties. Naturally it is a multidisciplinary organization where doctors of the different medical specialties work, in collaboration with engineers and technicians for maintenance, biomedical engineers for imaging, X Rays, equipment and instrumentation support and administrative and juridical personnel among many others.

Practically since its origins it has maintained academic relations with the Autonomous University of Mexico, fundamentally in the clinical training of doctors. In 1971 it was created an Experimental Medicine Unit and established within the Hospital. In this Unit medical personnel from the HGMEL collaborate with doctors from the UNAM's Medicine Faculty developing scientific projects. In 1996 the HGMEL and the UNAM celebrated a General Academic, Scientific and Cultural Collaboration Agreement with the objective of develop joint research projects, teach courses at the graduate level, train and interchange personnel, conduct seminars, make available the installations and equipment's 
to the counterpart, interchange scientific and technical information, interchange routine services and technical assistance.

However, the reached relationship between the medical areas wasn't enough to face the challenges of the new epidemics and 21st Century sicknesses so with notable vision, on January 24th, 2011, Dr. José Narro Robles, then UNAM's Rector created the program named Interdisciplinary Biomedicine Research Seminar (Seminario de Investigación Interdisciplinaria en Biomedicina, SIIB), with the objective of promoting space for researchers from different academic areas to present and promote their research projects, stimulating the linking and generation of original ideas applicable to health areas, to accelerate the innovation process, the development of talents and the transfer of research results to society. (Gaceta UNAM, 2011). To give it the required institutional solidity, the Seminar was in charge of the Secretariat of Institutional Development of the UNAM.

The Seminar organizer's proposed to carry out presentations and conferences with medical cases within the facilities of the Faculty of Medicine in University City, with the purpose of inviting and promoting the participation of physicists, doctors, engineers and other interested parties. Because of this, today the SIIB evolved and now is known as a Seminar of Linkage (Seminario de Vinculación) in the university environment. The Seminar's coordinators sent invitations for participating in the efforts to different entities of the UNAM's Scientific Research Coordination. Taking advantage of this, in 2011, several ICAT academics began their permanent participation in the Seminar establishing relationships with doctors from the Faculty of Medicine of the UNAM and the General Hospital of Mexico.

It took some time, but little by little, academic collaboration agreements were established through which the specifications of I \& DT projects were originated to help in the solution of some medical problems.

This was the antecedent for the creation of a Research and Technological Development Unit (UIDT) in the General Hospital of Mexico (HGM), Eduardo Liceaga. The UIDT's creation was due to the joint work of Dr. David Kersenovich then Research Director of the HGMEL, his assistance, Dr. Juan Carlos López Alvarenga and Dr. Francisco P. Navarro Reynoso, then General Director of the HGMEL, Dr. Crescencio García Segundo, from the ICAT academic group of Imaging and Medical Biophysics and Dr. José Manuel Saniger Blesa, then ICAT’s director. By 2011 a series of projects of interest to the parties were foreseen.

To formalize the UIDT's creation, UNAM through the ICAT and the HGMEL signed on February 29, 2012 a Specific Collaboration Agreement for academics and personnel defined by the parties to carry out interdisciplinary activities for the development and research of new technologies related to new materials, devices, equipment, software, diagnostic procedures, therapeutic procedures and support for professional practice and clinical teaching, related to pathologies and diseases of interest to the hospital and that affect the health of the Mexican people. The UIDT was inaugurated on September 20 $0^{\text {th }}, 2013$. By the end of 2013 and during 2014, Dr. Juan Carlos López Alvarenga was appointed HGMEL's Research Director and oversaw the UIDT's works.

Later ICAT became the gateway or link to formalize I\&DT projects carried out by academics from other university entities with the HGMEL. Thus, on February 9, 2015 the ICAT signed an Interinstitutional Collaboration Agreement with the Research Institute in Applied Mathematics and Systems to formalize the Institute's participation as a research institution of the UNAM, associated with the UIDT of the ICAT in the HGMEL. Today the UIDT's has a working space of $80 \mathrm{~m} 2$ within the Hospital where two UNAM- ICAT's academic researchers, one technical academic and a dozen of students work.

The validity of the basic Collaboration Agreement expired on February $29^{\text {th }}, 2014$. Both parts signed the First Modification Agreement on February $25^{\text {th }}, 2014$ extending the validity for two years up to February $25^{\text {th }}, 2016$. The parties agreed to sign again a Second Modification Agreement now for three years with validity from February $25^{\text {th }}, 2016$ up to February $25^{\text {th }}, 2019$.

To actualize the name of HGMEL's Research Director and ICAT's UIDT's Coordinator, a Third Modification Agreement was signed on March $20^{\text {th }}$, 2017.

\section{The UNAM-ICAT's/HGMEL Research and Technological Development Unit (UIDT) Today (ICAT, 2018)}

\subsection{Objectives and Staff}

Today the main objective of the UIDT is to develop research and technology on new materials, devices, equipment, software, diagnostics and therapeutic procedures as well as support for professional practice and clinical teaching related to diseases that affect the health of the general population. In the Unit there are installed four specialized and one general working areas. The multidisciplinary team is working in diverse projects, some of them already have approved protocols and other are in the process of being approved. In addition, some proposals are being studied for its realization.

The current staff of the HGMEL at the UIDT includes three research fellows and one coordinator. Additionally, more than 13 doctors working for HGMEL participate in UIDT projects 
The current staff of the ICAT at the UIDT includes three academic research fellows and one coordinator. Additionally, another 11 academics working for the ICAT participate in UIDT projects

\subsection{Ongoing Transdisciplinary Projects}

Beyond the multi and interdisciplinary knowledge required to carry out the I \& DT projects, the spirit that has encouraged the collaboration between the two governmental public institutions has been to carry out transdisciplinary projects with both characteristics, the different disciplines dominated by the participants and the expected high social impact of the resulting technology. According to Cardoso (1999), the tasks of public health require an interdisciplinary approach, and according to Rojas (2010), when the work is intersectoral, projects became transdisciplinary.

Some of the project with protocols approved by the different medical and ethical committees of the HGMEL, in different stages of development, are shown in Table I.

Table 1. Projects approved and under development at the UIDT

\begin{tabular}{ll}
\hline Nr. & Project Name \\
\hline $\mathrm{P}_{1}$ & $\begin{array}{l}\text { Optimization of the manufacturing process of PMMA craniofacial implants using additive } \\
\text { manufacturing techniques. }\end{array}$ \\
$\mathrm{P}_{2}$ & Thermography utility for diagnosis of micro or macro vascular sickness on diabetic foot \\
$\mathrm{P}_{3}$ & Prostate surgery simulator for training urological surgeons in transurethral resection. \\
$\mathrm{P}_{4}$ & Automated system for measuring and diagnosing Glaucoma (IIMAS) \\
$\mathrm{P}_{5}$ & $\begin{array}{l}\text { Design, development and validation of the potential of a UV fluorescence imaging technology for } \\
\text { the clinical management of skin wounds. (Evaluation of diabetic foot) }\end{array}$ \\
$\mathrm{P}_{6}$ & Photothermal response of mammary pathology in ex vivo as a probable diagnostic method. \\
$\mathrm{P}_{7}$ & Portable corneal topography \\
$\mathrm{P}_{8}$ & Hepatic tissue alterations study for chronic degenerative diseases using opto-thermal techniques \\
& implemented using optical fiber. \\
$\mathrm{P}_{9}$ & Low cost pressure sensors to measure alterations in footprint in eutrophic children with overweight \\
& and obesity \\
$\mathrm{P}_{10}$ & Ankylosing spondylitis. \\
$\mathrm{P}_{11}$ & Brachytherapy applicators manufacturing \\
\hline
\end{tabular}

4.3 Some Current Results

The trans-disciplinary projects mentioned above have different degrees of advance, in that regard many hardware and software prototypes have been built and some are in process of testing with patients in the application areas according with the corresponding protocols. In this section we discuss some results that have been obtained at the UIDT.

\subsubsection{Academic Products}

During the 5 years of operation of the UIDT several research articles have been published in indexed in instrumentation and medical Journals. Other academic products have been some theses for MSc, and BSc.

\subsubsection{Technology Transfer}

\subsubsection{Simulator for Training Surgeons on Laparoscopic Surgeries $\left(\mathrm{TT}_{1}\right)$}

This software was developed by UIDT's ICAT academics to help in the training of surgeons of the HGMEL's clinic of Gastroenterology to be trained in laparoscopic surgeries, it is in the process of testing and delivering.

\subsubsection{Facial-Skull Implants Prostheses Manufacturing Process $\left(\mathrm{TT}_{2}\right)$}

One of the results of the project "Optimization of the manufacturing process of PMMA craniofacial implants using additive manufacturing techniques" were the intellectual property copyrights and trademark obtained by the ICAT in 2015 including the industrial secret for the manufacturing process in 2017. Technology was developed by members of the National Additive Manufacturing Laboratory, 3D digitalization and Computerized Tomography" (MADIT, from Spanish) to help to fulfill the continuous requirement of skull prostheses at the Hospital.

The characteristics of the technology obtained overpasses the prostheses handmade process manufacturing improving time, quality and with $0 \%$ surgery rejections.

With the HGMEL's approval, in February 2017 a five years validity Technology Transfer and Licensing Agreement was 
signed between UNAM-ICAT and the firm Partes e Implantes Avanzados S.A. de C.V. The agreement objective is the exclusive licensing for manufacturing and selling in Mexico the technology named "Manufacturing process for skullfacial implants of Polymethyl Methacrylate (PMMA) using additive manufacturing techniques.

Although the sales potential of the technology is great, the main expectation is that PMMA digital implants could save about a 1000 lives a year since 2020, once the manufacturing shop be finalized and the permits from the Federal Commission for Protection against Health Risks (COFEPRIS from Spanish), be obtained.

\subsubsection{Technology Transfer of HepaScan System to the Pathology Service of HGMEL ( $\mathrm{TT}_{3}$ )}

The HepaScan System developed at ICAT helps with the quantification of the percentage of fibrosis and steatosis of images of histological sections of liver tissue. This software is a diagnosis auxiliary tool for liver diseases precursors of cirrhosis. The copyrights of the software were obtained by ICAT in 2017

The purpose of the transfer is to provide the Pathology Service of the HGMEL, a liver sample analysis tool that can be used in clinical diagnosis, research and teaching without limitation of use within the HGMEL. In return, the Pathology Service undertakes to express its gratitude to the development group of the ICAT-UIDT ICAT HGMEL in the publication and dissemination of works that contain results in which the HepaScan was used.

The use of the HepaScan will be exclusively for use in the Pathology Service and Medical Teaching, its use in other Services and Units of the HGMEL must be subject to a specific transfer agreement.

4.3.2.4 Simulator for training Surgeons on Laparoscopic Surgeries

This software was developed by UIDT's ICAT academics to help in the training of surgeons of the HGMEL's clinic of Gastroenterology to be trained in laparoscopic surgeries, it is in the process of testing and delivering.

\section{Discussion}

In Figure 2 we can observe different aspects of the dynamic organizational transition change occurred with the creation of UIDT. First, it is notable that phenomenon occurred as the result of the strategic partnership of both complex organizations, the HGMEL and ICAT.

Data corresponding to actions, authorities and personnel of HGMEL related to the UIDT's are in the superior part of the drawing. Correspondingly, data corresponding to actions, authorities and personnel of ICAT, related to the UIDT's are in the bottom part of the drawing. Remarkable phenomenon situations follow:

Time of changes

All the organizational dynamic change has occurred in a period of 5 to 6 years.

Authorities

In this period, there has been an intense change of authorities, since:

- The Directors of both institutions have change twice in each one of them

- The Research Directors at the HGMEL have change three times

- The UIDT's ICAT's Coordinators have change three times too.

Infrastructure

- It took the ICAT one and a half years after the celebration of the collaboration agreement to obtain from the HGMEL's authorities the engineered working area space of $80 \mathrm{~m} 2$, conditioned with Internet, Phone lines, working spaces separations, painted and ready to work.

- The HGMEL's also give ICAT al office within the Oncology Hospital, that later was occupied by nursery people since there were no constant presence of ICAT's people.

\section{Interdisciplinary Projects}

- Although that there were several initial prospect projects cited at the initial collaboration agreement, just two or three of those projects were protocolized and are part of the actual project portfolio.

- Using a strategy of open seminars with the participation of academics and researchers of both institutions, eleven projects are included in the actual UIDT's project portfolio

\section{Technology Results}

After five years, some UIDT's results have begun to appear, among them a simulator to teach medical students laparoscopic surgery, a thermo-graphic system with software used for diagnostic of diabetic foot, a manufacturing process of PMMA craniofacial implants using additive manufacturing techniques transferred to an external firm for its production and sales, and a software called HepaScan transferred from the ICAT to the Pathology HGMEL's service to help with the diagnostic of precursor diseases of cirrhosis.

The transition overshoots 
Figure 2 also shows the UIDT's creation transition. Since it can be understood as a first order change for the partners, it constituted a second order change for de UIDT itself. According with that, Figure shows a clear overshoot occurring before the first two years of UIDT's creation. There were no academic people from the ICAT working directly at the UIDT and there were just a few students working in their bachelors or MSc theses at UIDT's laboratory. There were no projects with protocols approved, nor investigation infrastructure equipment and instruments. In synthesis, apparently there wasn't a developing plan to follow. The origin of this problem was that two complex organizations as HGMEL and ICAT conform a strategic alliance to create the UIDT; then, ¿how the UIDT stakeholders overcome the change factors?

\section{Controlling the overshoot}

Starting from the base that any organizational change has a number of change factors, and that some of they are the Complexity factor, related to the large number of variables and interactions among them, the Epistemic factor, related to the persistent mental models of the stakeholders, the Structural factor regarding the fundamental concept that when look for different behavior from an existing one in the organization, it would require a different underlying structure and finally the Inertia or resistance to change factor. These factors are not only obstacles for change but when management does not use the antidotes for them, they drive organizations into crisis conditions of requiring second order change interventions. Nevertheless, we can take advantage of the fact that a complex organization is a social system that may adapt to changes in their environments using reflexive mechanisms as adaptation and learning. Therefore, to control the overshoot, Dr. José Manuel Saniger Blesa, then ICAT's director made the requirement to Dr. Carlos Aramburo de la Hoz, Scientific Research Coordinator, of hiring of a research fellow and an academic technician to work directly at the UIDT's installations. This was approved and carried on at mid-2016.

Apparently, these hiring were the control mechanism that damped the organizational oscillations because in short time projects protocols began to be approved and results did not take long to appear.

\section{Conclusions}

Hoang \& Rothaermel (2016), proposed a strategic approach for managing alliances strategically, overcoming the initial assumptions that not always pass: (1) the organization will find good partners, (2) it will be able to capture a reasonable amount of value from its partnerships, (3) the alliances will continue to serve the organization's needs overtime. They point out that organization must have special care in the selection of partners, deal a good negotiation, execute it and have in hand an explicit exit planning in the case the alliance dissolution be needed and always having an alliance portfolio to reconfigure its network.

HGMEL and ICAT have been good partners, its partnership is giving them value results and seem this will continue happen in the middle future. Both parts are thinking in stabilize UIDT's operations and make it stronger in the coming years, planning to carry on larger trans-disciplinary projects.

The initial confusion was generated because of languages, expectative and perceptions differences and ambiguous governance; nevertheless, parts have been learning to collaborate to develop new technology knowledge, it has been an opportunity for knowledge translation in benefit of patients.

The creation of the UIDT produces a differentiation of the organizations that means that partners became different from the way they used to be. 


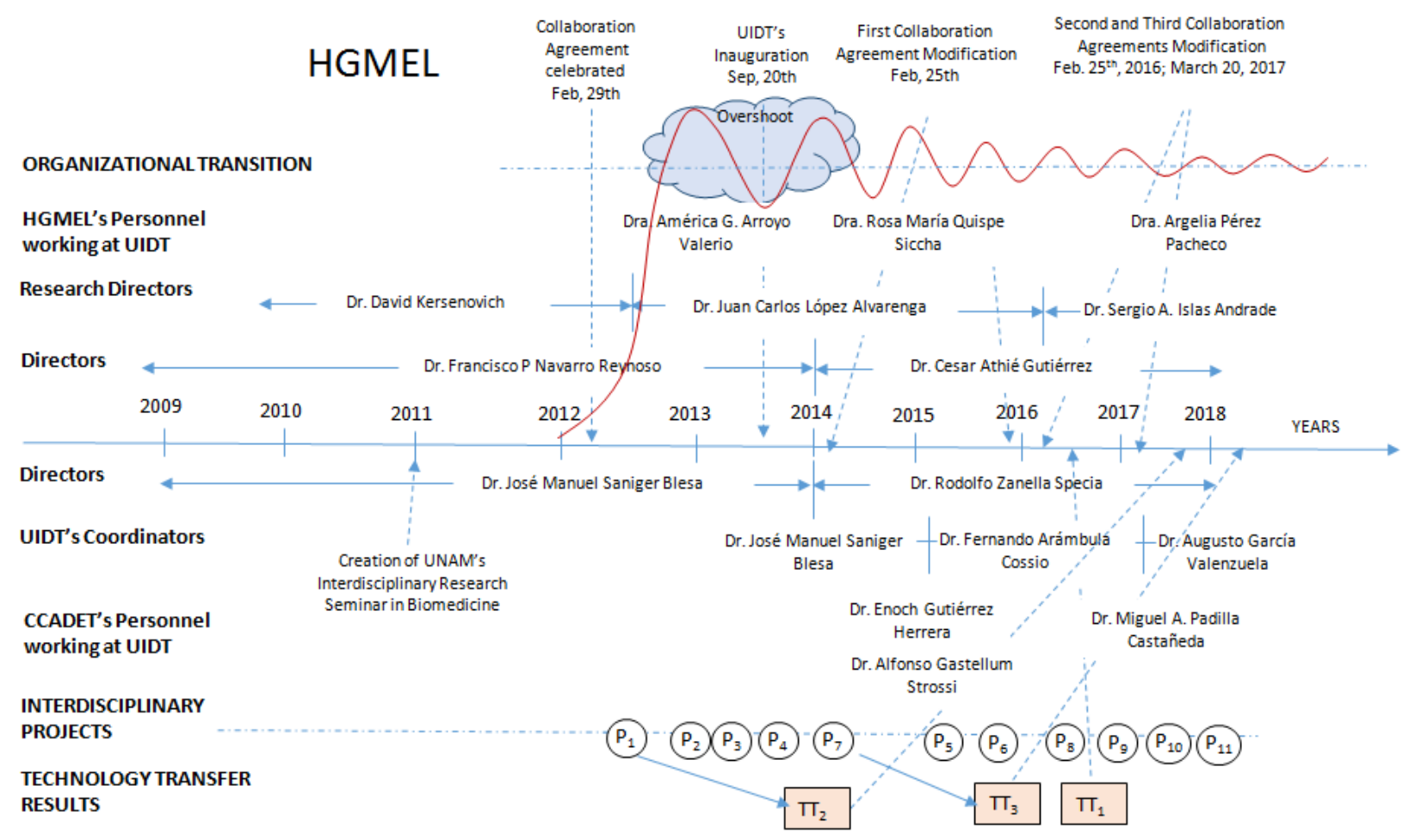

CCADET

Figure 2. Evolution and organizational transition of UIDT

\section{References}

Bate, P. (1994). Strategies for cultural change. Oxford: Butterworth-Heinemann.

Ben-Eli, M. U. (2008). Why is managing change difficult? Organizational renewal and the cybernetics of effective enterprise. International Journal of Applied Systemic Studies, 2(1/2), 146-158. https://doi.org/10.1504/IJASS.2008.022800

Buse, K., \& Harmer, A. M. (2007). Seven habits of highly effective global public-private health partnerships: Practice and potential. Social Science \& Medicine, 64, 259-271. https://doi.org/10.1016/j.socscimed.2006.09.001

Calvin, S. W., Wen-Goang, Y., \& Kuei-Kuei, L. (2014). Technological position in alliances network. Technology Analysis \& Strategic Management, 26(6), 669-685. http://dx.doi.org/10.1080/09537325.2014.923096

Cardoso, G. M. A. (1999). Interdisciplina o multidisciplina en el área de la salud. Salud Problema, 4(7), 31-37.

Chang, C. K. N., Shipp, S. S., \& Wang, A. J. (2002) The Advanced Technology Program: A public-private partnership for early stage technology development, Venture Capital, 4(4), 363-370. https://doi.org/10.1080/1369106022000028262

Chesbrough, H. W., Vanhaverbeke, W., \& West, J. (2006) Open innovation: researching a new paradigm. [e-book], Oxford: Oxford University Press.

Das Rajesh Kumar, T. K. (2011) Interpartner negotiations in alliances: a strategic framework. Management Decision, 49(8), 1235-1256. Available at http://dx.doi.org/10.1108/00251741111163106. https://doi.org/10.1108/00251741111163106

De Rond, M., \& Bouchikhi, H. (2004). On the dialectics of Strategic Alliances. Organization Science, 15(1), 56-69. ISSN 1047-7039. https://doi.org/10.1287/orsc. 1030.0037

Gulati, R. (1998). Alliances and networks. Strategic Management Journal, 19(4), 293-317. https://doi.org/10.1002/(SICI)1097-0266(199804)19:4<293::AID-SMJ982>3.0.CO;2-M

Gustafsson, O., \& Magnusson, J. (2016). Inter-Organizational Collaboration in Theory and Practice: Based on a multiple 
case study in the automotive industry. Master These, Department of Technology Management and Economics. Division of Entrepreneurship and Strategy. Chalmers University of Technology. Gothenburg, Sweden 2016

Hoang, H., \& Rothaermel, F. T. (2016). How to Manage Alliances Strategically. MIT Sloan Management Review. Massachusetts Institute of Technology, 1-8. Reprint \#58119 http://mitsmr.com/2bfqMhG

Ho-Sung, K., \& Sun-Young, Ch. (2014). Technological alliance portfolio configuration and firm performance. Rev Manag Sci, 8, 541-558.

Huxham, C., \& Vangen, S. (2005). Managing to collaborate: the theory and practice of collaborative advantage. London and New York: Routledge.

ICAT (2018). Unidad de Investigación y Desarrollo Tecnológico del ICAT en el Hospital General de México. Available at: http://www.ICAT.unam.mx/secciones/depar/sub5/unhgm.html

Kaats E, \& Opheij W. (2012). Learning to collaborate between organizations (in Dutch: Leren samenwerken tussen organisaties). Kluwer, Deventer

Kaats E., \& Opheij, W. (2014). Creating Conditions for Promising Collaboration: Alliances, Networks, Chains, and Strategic Partnerships. Springer Briefs in Business. ISBN 978-3-642-41443-5 (eBook).

Kim. J. (2015). Performance-based development funding using market mechanisms: A public-private partnership social financing model for medical equipment technology in developing countries. Progress in Development Studies, 15, (3), 257-269. https://doi.org/10.1177/1464993415578982

Lerner, J., \& Merges, R. P. (1998). The Control of Technology Alliances: An Empirical Analysis of the Biotechnology Industry. The Journal of Industrial Economics, 46(2), 125-156. Blackwell Publishing. URL: http://www.jstor.org/stable/117546.

Leydesdorff, L. (1997) Sustainable technological developments and second-order cybernetics. Technology Analysis \& Strategic Management, 9(3), 329-343. https://doi.org/10.1080/09537329708524288

Lichtenthaler, U. (2011) Open innovation: past research, current debates, and future directions. The Academy of Management Perspectives, 25(1), 75.

Lin, H., \& Darnall, N. (2014). Strategic Alliance Formation and Structural Configuration. J. Bus Ethics, 125, 549-564. https://doi.org/10.1007/s10551-014-2053-7

Lorenzi, N. M., \& Riley, R. T. (2000). Managing Change: An Overview, Journal of the American Medical Informatics Association, 7(2), 116-124. https://doi.org/10.1136/jamia.2000.0070116

Mantoura, P., Gendron, S., \& Potvin, L. (2007). Participatory research in public health: Creating innovative alliances for health. Health \& Place, 13, 440-451. https://doi.org/10.1016/j.healthplace.2006.05.002

Nadler, D. A., \& Tushman, M. L. (1995). Types of organizational change: From incremental improvement to discontinuous transformation. In Discontinuous change: Leading organizational transformation, ed. D. A. Nadler, R. B. Shaw, A. E. Walton, and Associates, 15-34. San Francisco: Jossey-Bass.

Narro, R. J. (2011). Acuerdo por el que se establece el Programa denominado Seminario de Investigación Interdisciplinaria En Biomedicina. Gaceta UNAM, 24 de enero.

Nelson, J. C., Raskind-Hood, Ch., Galvin, V. G., Essien, J. D. K., \& Levin, L. M. (1998). Positioning for Partnerships: Assessing Public Health Agency Readiness. American Journal of Preventive Medicine, 16(3S), 103-117.

Newman, K. L. (2000). Organizational transformation during institutional upheaval. Academy of Management Review. 25(3), 602-619. https://doi.org/10.5465/amr.2000.3363525

Paixão, G. M., Sbragia, P., \& Kruglianskas, I. (2014). Factors for selecting partners in Innovation Projects - Evidences from alliances in The Brazilian Petrochemical leader. Revista de Administração e Inovação, São Paulo, 11(2), 241272. https://doi.org/10.5773/rai.v11i2.1292

Parker, D., \& Hartley, K., (2003). Transaction costs, relational contracting and public private partnerships: a case study of UK defense. Journal of Purchasing \& Supply Management, 9, 97-108. https://doi.org/10.1016/S0969-7012(02)00035-7

Peters, D. H., \& Muraleedharan, V. R. (2008) Regulating India's health services: To what end? What future? Social Science \& Medicine, 66, 2133-2144. https://doi.org/10.1016/j.socscimed.2008.01.037

Porter, M. E., \& Kramer, M. R. (1999). Philanthropy's new agenda: creating value. Harvard Business Review, 77(6), 121130. 
Ramiah, I., \& Reich, M. R. (2006). Building effective public-private partnerships: Experiences and lessons from the African Comprehensive HIV/AIDS Partnerships (ACHAP). Social Science \& Medicine, 63, 397-408. https://doi.org/10.1016/j.socscimed.2006.01.007

Rojas, O. F. (2010). Interdisciplina e Intersectorialidad. Revista Cubana de Salud Pública, 36(3), 197. https://doi.org/10.1590/S0864-34662010000300001

Sheikh, K., Porter, J., Kielmann, K., \& Rangan, S. (2006). Public-private partnerships for equity of access to care for tuberculosis and HIV/AIDS: lessons from Pune, India. Transactions of the Royal Society of Tropical Medicine and Hygiene, 100, 312-320. https://doi.org/10.1016/j.trstmh.2005.04.023

Sociedad Médica del Hospital General A. C. (2016). Historia del Hospital General de México. Disponible en http://www.smhg.org.mx/historia-hgm

Stone, V. I., \& Lane, J. P. (2012). Modeling technology innovation: How science, engineering, and industry methods can combine to generate beneficial socioeconomic impacts. Implementation Science, 7(44), 1-19. Available at http://www.implementationscience.com/content/7/1/44. https://doi.org/10.1186/1748-5908-7-44

Suarez-Balcazar et al. (2005). An interactive and contextual model of community-university collaborations for research and action. Health Education Behavior, 32 (1), 84-101. https://doi.org/10.1177/1090198104269512

Tripon, C., \& Dodun M. (2011) Change Management and Organization Development. Available at: http://www.apubb.ro/wp-content/uploads/2011/02/OD_Suport_de_curs_masterat.pdf

Watzlawick, P., Weakland, J., \& Fisch, R. (1974). Change: Principles of Problem Formation and Problem Resolution. W.W. Norton. New York.

Wikipedia (2018). Hospital General de México. Available at: https://es.wikipedia.org/wiki/Hospital_General_de_M\%C3\%A9xico

Wohlstetter, P., Smith, J., \& Malloy, C. L. (2005). Strategic Alliances in Action: Toward a Theory of Evolution. The Policy Studies Journal, 33(3), 419-442. https://doi.org/10.1111/j.1541-0072.2005.00123.x

Zisuh, N. (2009). The emergence of global health partnerships as facilitators of access to medication in Africa: A narrative policy analysis. Social Science \& Medicine, 68, 949-956.

https://doi.org/10.1016/j.socscimed.2008.12.027

\section{Copyrights}

Copyright for this article is retained by the author(s), with first publication rights granted to the journal.

This is an open-access article distributed under the terms and conditions of the Creative Commons Attribution license which permits unrestricted use, distribution, and reproduction in any medium, provided the original work is properly cited. 